\title{
Gastrointestinal side effects of immune checkpoint inhibitors: new topic for gastroncologists
}

\author{
Semra Paydas* \\ Cukurova University Faculty of Medicine Dept of Medical Oncology Adana, Turkey
}

\begin{abstract}
Immune checkpoint inhibitors (ICIs) are important novel drugs in cases with different types of cancers including malignant melanoma, non-small cell lung cancer, renal cell cancer, urothelial cancers, Hodgkin lymphoma, hepatocellular cancer, head and neck cancer, Merkel cell cancer and also mismatch repair-deficient solid tumors. Immune checkpoint blockade increases anti-tumor immunity by blocking intrinsic downregulators of immunity, such as cytotoxic T-lymphocyte antigen 4 (CTLA-4) and programmed cell death 1 (PD-1) or its ligand, programmed cell death ligand 1(PD-L1). However these blockers have some immune-related side effects. Gastointestinal tract and liver are affected from these drugs. Here these side effects and their management have been reviewed.
\end{abstract}

Core tip: Immune checkpoint inhibitors (ICIs) are important agents in cases with different types of cancers. Immune checkpoint blockade increases anti-tumor immunity by blocking intrinsic downregulators of immunity, such as cytotoxic T-lymphocyte antigen 4 (CTLA-4) and programmed cell death 1 (PD-1) or its ligand, programmed cell death ligand $1(\mathrm{PD}-\mathrm{L} 1)$. However these blockers have many immune-related side effects. Gastointestinal tract and liver are affected from these drugs. Here incidence, timing and management of these side effects have been reviewed.

\section{Introduction}

Immune checkpoint inhibitors (ICIs) are important drugs in cases with different types of cancers including malignant melanoma, nonsmall cell lung cancer, renal cell cancer, urothelial cancers, Hodgkin lymphoma, hepatocellular cancer, head and neck cancer, Merkel cell cancer and also mismatch repair-deficient solid tumors. Immune checkpoint blockade increases antitumor immunity by blocking intrinsic downregulators of immunity, such as cytotoxic T-lymphocyte antigen 4 (CTLA-4) and programmed cell death 1 (PD-1) or its ligand, programmed cell death ligand $1(\mathrm{PD}-\mathrm{L} 1)$.

First monoclonal antibody showing impressive clinical activity is CTLA-4 inhibitor ipilimumab in malignant melanoma and then good results have been reported with PD-1/PD-L1 inhibitors including nivolumab, pembrolizumab, durvalumab, atezolizumab, avelumab etc. Although these drugs have important roles in augmenting T-cell specific and durable responses in clinical practice, they cause inflammatory side effects. Systemic and organ-specific side effects of ICIs are classified as immune related adverse events (irAEs) [1-3]. Although almost all the organs are injured by these side effects irAEs are seen most commonly in gastrointestinal (GI) tract, in the liver, endocrine glands, and skin. Management of irAEs require multidisciplinary collaboration between oncologists and gastroenterologist: gastroenteroncologist will be an important term in next years due to the wide spectrum of these side effects. Figure 1 shows side effects of the ICIs [2]. CTLA-4 inhibits immune response by attenuating T-cell activation at a proximal step while PD-1 inhibits T cells at later stages of the immune response in peripheral tissues. For this reason toxicity profile of these blockers are different. Many cytokines have important roles in the pathophysiology of irAEs [2,4-8].

Here gastrointestinal, hepatic and pancreatic irAEs and management of toxicity of monoclonal antibodies targeting CTLA- 4 and PD-1/PDL1 system will be discussed. Ipilimumab is the most frequently used anti-CTLA-4 monoclonal antibody while nivolumab, pembrolizumab, atezolizumab are the most frequently used monoclonal antibodies targeting PD-1/PD-L1 system [9]. An important strategy is to combine these two antibody systems with higher incidence and changing toxicity profile. Liver and GI toxicities are seen in $14^{\text {th }}$ and $26^{\text {th }}$ weeks of the nivolumab therapy while these toxicities are seen in $7^{\text {th }}$ week of the ipilimumab-nivolumab combinations [10]. Some fo the irAEs can be severe enough and requiring discontinuation or interruption of these drugs. Early diagnosis and appropriate treatment of ir AEs are important to reduce morbidity and also mortality

\section{Time, cumulative toxicity and genetic factors for} immune-related adverse events

irAEs generally develop within the first weeks but may be seen several months after ICI treatment and even can be seen after discontinuation of the therapy. However, there is no clear evidence of cumulative toxicity or safety in long term users of PD-1/PD-L1 inhibitors [11]. There is evidence of some genetic factors including microbiologic composition of patients gastrointestinal flora related to the development of irAEs $[12,13]$. Figure 2 shows the timing the occurrence of irAEs [14].

${ }^{\star}$ Correspondence to: Semra Paydas MD Prof, Cukurova University Faculty of Medicine Dept of Medical Oncology Adana, Turkey, E-mail: sepay@cu.edu.tr

Key words: immune checkpoint blocker, PD-1, PD-L1, CTLA-4, immunotherapy, adverse effects, hepatotoxicity, GI toxicity

Received: May 19, 2019; Accepted: June 10, 2019; Published: June 13, 2019 


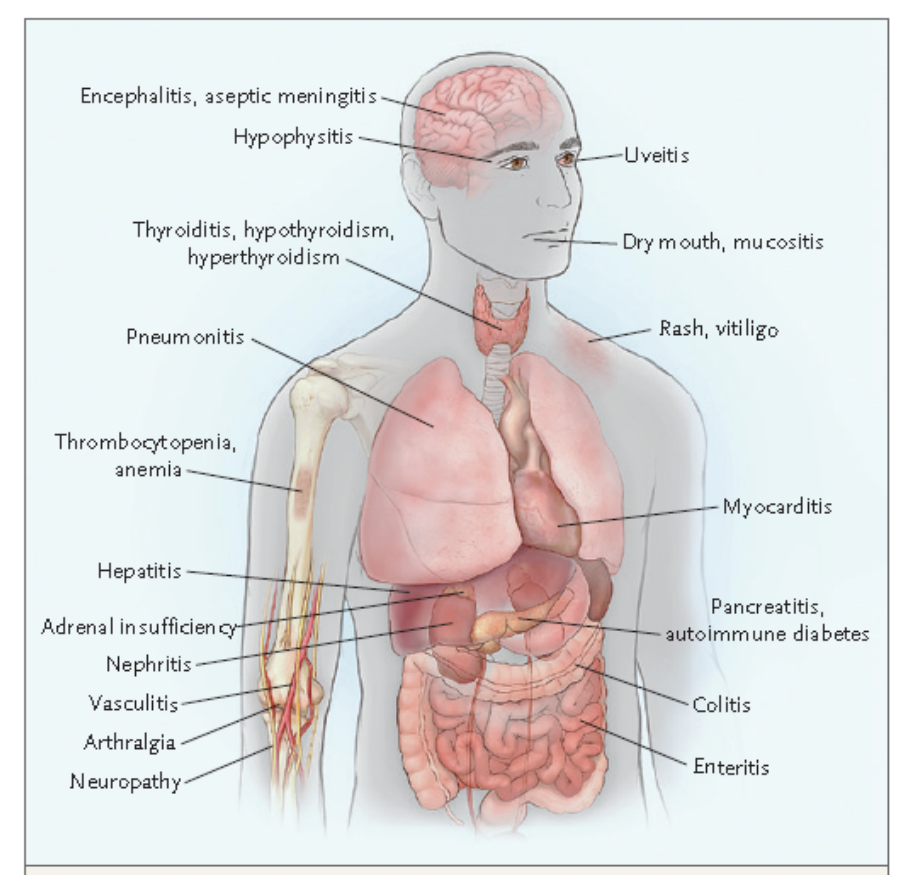

Figure 1. Organs affected by immune checkpoint blocker treatments (Reprinted from reference 2)

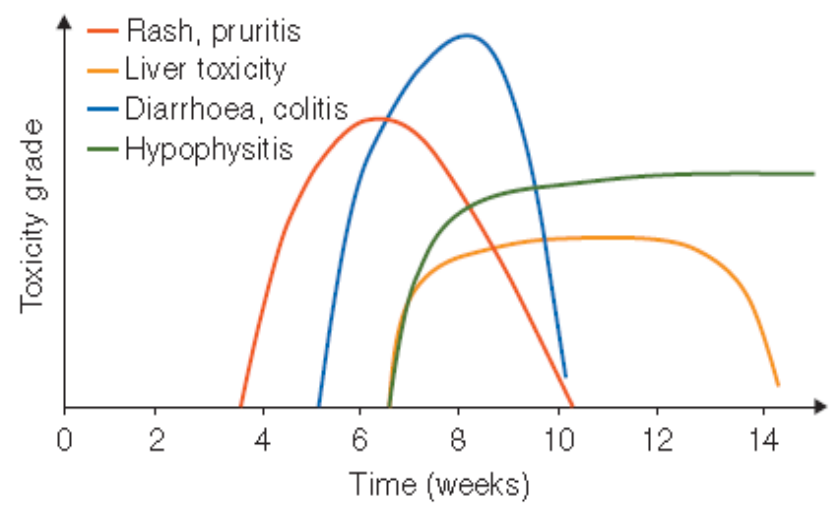

Figure 2. Timing of occurence of immune-related adverse events following ipilimumab treatment (Reprinted from reference 14)

\section{Immune related hepatotoxicity}

\section{Definition}

Liver is a key target organ for autoimmune toxicity ,named as immune-related hepatotoxicity or immune-mediated hepatitis [3].

\section{Incidence}

Hepatitis occurs in $1-10 \%$ of the cases treated by single agent ipilimumab, nivolumab or pembrolizumab and 1-2\% of these are grade III $[15,16]$. Although clinically significant hepatotoxicity is less common than other organ toxicities, fatal immune-related liver injury has been reported in some clinical studies and especially in post-marketing setting. For this reason early diagnosis and appropriate management are critical points [17]. Hepatitis occurs generally after 8-12 weeks of the initiation of ICI therapy but may be seen within 8 days or 21 months after therapy [7]. Incidence and severity of ICI-related hepatic toxicity has been shown in Table 1 [17].
Elevated AST and ALT levels have been reported in 2-5\% of the cases in a meta-analysis covering 46 clinical trials of anti-PD-1 agents (nivolumab, pembrolizumab, atezolizumab, durvalumab, avelumab, BMS-936559). Increased bilirubin levels have been reported in 1-2\% of the cases. Higher incidence of toxicity has been reported in patients treated with combinations in up to $30 \%$ of the cases and $\geq$ grade III toxicity has been reported in $6-19 \%$ of these cases [7,18-23].

\section{Onset, severity and predisposing/risk factors for liver toxicity}

Immune mediated hepatitis ranges in severity between mildmoderate to life-threatening and simulate idiopathic auto-immune hepatitis. ICI-induced liver injury is depend on:

1-Type of molecule: CTLA-4 or PD-1/PD-L1,

2-ICI-dose level : In cases treated by ipilimumab, the rates of grade IIIIV irAEs are seen in $0 \%, 7 \%$ and $25 \%$ of the cases treated with $0.3 \mathrm{mg} /$ $\mathrm{kg}, 3 \mathrm{mg} / \mathrm{kg}$ and $10 \mathrm{mg} / \mathrm{kg}$; respectively [24],

3-CTLA-4, PD-1/PD-L1 combinations cause more toxicity as compared with single agent using $[25,26]$,

4- Underlying subclinical form of idiopathic autoimmune hepatitis may be predictive for more severe autoimmune liver injury [27],

5-Chronic liver infection is an important predictive factor for higher grade ICI-induced liver injury,

6-Liver parenchymal disease due to underlying tumor is an important factor for liver injury [3].

The most important factors in the management of liver toxicity are assessment the cause of liver injury, optimal management and monitoring of ICI related toxicity, critical decision to continue or to discontinue ICI treatment and also the use of steroidal or immunosuppressive drugs. For these reasons regular monitoring of liver function tests during and also after treatment with ICIs is critically important to prevent risk of serious adverse events . CTLA-4 blocker ipilimumab causes more liver toxicity than PD-1 blockers and patients treated by ipilimumab must be monitored more closely [3].

Patients with chronic viral hepatitis or human immunodeficiency virus (HIV) infection have generally been excluded from trials with immune checkpoint blockade. However, similar side effects have been reported in cases with hepatocellular cancer treated by nivolumab in a prospective study in patients with or without hepatitis $\mathrm{B}$ or hepatitis $\mathrm{C}$ related hepatitis [28].

Higher incidence and grade III-IV hepatotoxicity have been found in cases with hepatocellular cancer treated by nivolumab. More severe hepatotoxicity is attributed to additive effects of tissue autoantigen release due to tumor infiltration and also viral damage in conjunction

Table 1. Hepatotoxicity associated with ICI [17]

\begin{tabular}{|l|l|l|l|}
\hline Mo Ab & Target & $\begin{array}{l}\text { Incidence (\%) } \\
\text { (fatal*) }\end{array}$ & $\begin{array}{l}\text { Median time to } \\
\text { onset (month) }\end{array}$ \\
\hline Ipilimumab & CTLA-4 & $4-11,\left(0.2^{*}\right)$ & $1.4-2$ \\
\hline Pembrolizumab & PD-1 & 0.7 & 1.3 \\
\hline Nivolumab & $\begin{array}{l}1.8(13 \text { with } \\
\text { ipilimumab } \\
\text { combination) }\end{array}$ & $\begin{array}{l}3.3(2.1 \text { with } \\
\text { ipilimumab } \\
\text { combination) }\end{array}$ \\
\hline Atezolizumab & PD-L1 & $0.9-1.3,\left(0.1^{*}\right)$ & $0.9-1.1$ \\
\hline Avelumab & $0.9,\left(0.1^{*}\right)$ & 3.2 \\
\hline Durvalumab & & $1.1,\left(0.1^{*}\right)$ & 1.7 \\
\hline
\end{tabular}


with ICI-induced the autoreactive T cell activity. Grade III-IV ALT, AST and bilirubin increases have been found in $18 \%, 11 \%$ and $7 \%$; respectively. Systemic steroids have been found to be necessary in only $5 \%$ of the cases [29].

\section{Clinical presentation and diagnosis of liver toxicity}

Patients are generally asymptomatic but some patients have fever, fatigue or jaundice. Fulminant hepatitis has been reported [29]. Serum transaminase and bilirubin levels must be monitored in all cycles in cases treated by ICI [3,7]. Diagnostic evaluation should rule out other etiologic factors [7]. Hepatotoxicity associated with ICIs may be in hepatocellular or cholestatic pattern and variable from mild abnormal laboratory findings to acute liver failure [30]. Typically hepatic injury is seen 1-3 months after ICI treatment but may be seen after longer period of treatment and even after discontinuation of the drug [3].

Imaging studies are not sensitive or specific for ICI-induced hepatotoxicity, but bile duct obstruction due to cholelithiasis, liver metastatic disease and vascular obstruction must be ruled out with imaging modalities [7]. Radiologic findings are normal in mild/ moderate cases. Periportal lymphadenopathy, periportal edema and hepatomegaly have been reported in cases with severe hepatotoxicity $[29,30]$. Concomittant drug using, alcohol, underlying disease causing hepatic dysfunction, infections especially viral infections must be considered and evaluated in cases developing hepatic dysfunction. Liver biopsy is necessary in cases with severe hepatic toxicity [31]. The most commonly seen hepatic dysfunction is lobular hepatitis and most commonly zone 3 is affected and this entity mimics autoimmune hepatitis $[3,29,32]$.

Histopathologic findings Sinusoidal histiocytosis and central vein endothelitis suggest ICI related inflammation. Portal tract inflammation and cholangitis may be seen and this may mimic non alcoholic steatohepatitis [17]. Portal and peri-portal inflammation and hepatocellular necrosis with infiltrating lymphocytes, plasma cells and eosinophils have been reported in 5 cases treated by ipilimumab with severe hepatic toxicity [33]. Panlobular hepatitis or bile duct injury have been reported in cases treated by ipilimumab but these are not specific for ICI related hepatotoxicity [33,34].

Recent studies show higher clinical activity in cases treated by CTLA4 and PD-1 combinations and ICIs and tyrosine kinase inhibitors with more toxicity especially irAEs. Higher ipilimumab dosing schedules cause more toxicity [3]. Table 2 shows the onset, incidence, grading and management of hepatotoxiciy in cases treated by ICIs.

\section{Management of liver toxicity}

Routine clinical and laboratory assessments are critical for early detection and mitigation of ICI-induced hepatotoxicity. US FDA recommend monitoring laboratory tests including AST, ALT, bilirubin and clinical signs and symptoms before each dose, at periodic intervals and after discontinuation of treatment, and also when clinically indicated [35].

Corticosteroids are recommended in cases developing $\geq$ grade II toxicity. Persistent grade II elevations lasting more than 1-2 weeks require $1 \mathrm{mg} / \mathrm{Kg}$ methylprednisolene or equivalent corticosteroid. However other causes of hepatic dysfunction must be ruled out before steroid therapy. Hepatitis generally responds to corticosteroids within 8 weeks but relapses are frequent when tapered this drug [36]. ICI may be re-started in case of improvement of liver function tests. Corticosteroid dose must be increased to $2 \mathrm{mg} / \mathrm{Kg}$ if liver function tests do not improve
Table 2. Management ICI related hepatotoxicity

\begin{tabular}{|c|c|c|}
\hline Hepatotoxicity & $\begin{array}{l}\text { AST or ALT x } \\
\text { upper limit of } \\
\text { normal }\end{array}$ & Management \\
\hline Grade I & $\leq 3$ & $\begin{array}{l}\text { *Continue ICI } \\
\text { *Repeat LFTs in } 1 \text { week }\end{array}$ \\
\hline Grade II & $3-5$ & $\begin{array}{l}\text { *Hold ICI } \\
\text { *Re-check INR/LFTs/albumin in every } 3-5 \text { days } \\
\text { *If AST/ALT is elevating: start oral prednisolone } \\
0.5-1 \mathrm{mg} / \mathrm{kg}\end{array}$ \\
\hline Grade III & $5-20$ & $\begin{array}{l}\text { *Permanently discontinue ICI } \\
\text { * Monitor AST, ALT, INR, albumin every } 1-2 \\
\text { days } \\
\text { *US with Doppler } \\
\text { *AST/ALT }<400 \text {, INR, albumin, bilirubin } \\
\text { normal: start oral prednisolone } 1-2 \mathrm{mg} / \mathrm{kg} \\
\text { *AST/ALT }>400 \text { or bilirubin } \uparrow, \text { INR } \uparrow \text {, albumin } \downarrow \text { : } \\
\text { start IV (methyl)prednisolone } 2 \mathrm{mg} / \mathrm{kg} \\
\text { *If steroid refractory or or no improvement after } \\
3 \text { days, consider MMF } \\
\text { *Do not use infliximab }\end{array}$ \\
\hline Grade IV & $>20$ & $\begin{array}{l}\text { *Permanently discontinue ICI } \\
\text { *Hepatology consultation } \\
\text { *Consider liver biopsy } \\
\text { *Start IV (methyl)prednisolone } 2 \mathrm{mg} / \mathrm{kg}- \\
\text { hospitalization } \\
\text { * Monitor liver enzymes daily } \\
\text { *If steroid refractory or or no improvement after } \\
3 \text { days, consider MMF } \\
\text { *Do not use infliximab }\end{array}$ \\
\hline \multicolumn{3}{|c|}{$\begin{array}{l}\text { Rule out } \\
\text { *viral etiology including Hepatitis A,B,C serology, hepatitis E PCR, } \\
\text { *disease related hepatic dysfunction, other drug-induced transaminase elevations } \\
\text { including statins, antibiotics, alcohol, } \\
\text { *limit/discontinue probable hepatotoxic medications } \\
\text { *anti-ANA/SMA/LKM/SLA, LP, LCI, iron studies } \\
\text { * Imaging for metastases or clot }\end{array}$} \\
\hline \multicolumn{3}{|c|}{$\begin{array}{l}\text { Steroid dosage } \\
\text { G2 once G1: wean over } 2 \text { weeks, re-escalate if worsens, treatment may be resumed once } \\
\text { prednisolone } \leq 10 \mathrm{mg} \\
\text { G3/4: once improved to G2, can change to oral prednisolone and wean over } 4 \text { weeks; for } \\
\text { G3 rechallange only at consultant discretion } \\
\text { Worsening despite steroids: If on oral change to IV (methyl)prednisolone } \\
\text { If on IV add MMF 500-1000 mg bd } \\
\text { If worsen on MMF, consider addition of tacrolimus } \\
\text { Consider ATG in steroid+MMF refarctory (case report ESMO 31) }\end{array}$} \\
\hline
\end{tabular}

Abbreviations: ALT: alanine transaminase; AST: aspartate transaminase; ANA: antinuclear antibodies; bd: twice daily; ICI: immune-cehckpoint inhibitor; INR: international normalised ratio; IV: intra venous; LCI: lung clearance index; LFT: liver function test; LKM: liver kidney microsomal; MMF: mycophenolate mofetil; PCR: polymerase chain reaction; SLA/LP: soluble liver antigen/liver-pancreas antibody; SMA: smooth muscle autoantibody; ULN: upper limits of normal; US: ultrasound

Note: This table has been modified from NCCN and ESMO guidelines

or worsen. If there is no improvement in liver tests in cases treated by higher doses of steroid and also in the presence of $\geq$ grade III toxicity ICI must be stopped permanently. Transaminases and bilirubin levels must be monitored twice weekly. If there is no response to $2 \mathrm{mg} /$ $\mathrm{Kg}$ steroid within 2-3 days mycophenolate mofetil must be added at $1000 \mathrm{mg}$ twice daily. The efficacy of $\mathrm{N}$-acethylcysteine, ursodeoxycholic acid or budesonide on the rapid normalization of liver function tests are not clear [37].

Liver biopsy is recommended in cases refractory to steroid and mycophhenolate mofetil $[3,38]$. Infliximab is not used in the therapy of ICI-related hepatitis due to the risk of hepatotoxicity of tumor necrosis factor alpha inhibitors $[7,17,39]$. Anti-thymocyte globulin (ATG) may be used for ipilimumab related hepatic toxicity refractory to steroid and mycophhenolate mofetil treatment. Tacrolimus is a third line choice as immunosuppressive drug. Hepatitis resolves within 4-6 weeks with appropriate treatment. If there is no improvement other contributing 
factors must be considered and diagnostic procedures must be repeated carefully. Hepatotoxic drugs, herbal medications and also CMV reactivation must be considered carefully.

\section{Gastrointestinal tract toxicity}

\section{Definition}

The term colitis defines abdominal pain or endoscopic/radiologic evidence of colonic inflammation [7].

\section{Incidence}

GI tract toxicity is the most frequently irAE in patients treated by anti-CTLA-4 antibody causing to discontinuation of this drug $[7,40]$. Diarrhea occurs in $27-54 \%$ of patients treated with anti-CTLA-4 monoclonal antibody. About one third of the cases have diarrhea and $8-22 \%$ of the cases have colitis $[20,21,41]$. Colon perforation has been reported in $1-1.5 \%$ in cases treated for melanoma and $6.6 \%$ of the cases treated for renal cell cancer related to ipilimumab-induced enterocolitis [41-44]. CTLA-4-induced eneterocolitis risk has been found to be higher in cases receiving non-steroidal anti-inflammatory drugs [45]. There is limited data about the immune-related colitis in patients with underlying ulcerative colitis or Chron's disease; in a small study ipilimumab-induced colitis or disease relapse has been reported in 2 out of 6 cases [46].

Diarrhea and colitis incidence in cases treated by PD-1/PD-L1 blockers are lower than ipilimumab treated cases: $11-19 \%$ and 1-4\%; respectively and grade III-IV toxicity is seen in $1-3 \%$ of the cases. However diarrhea and colitis incidence are highest in cases treated by CTLA- 4 and PD-1/PD-L1 blocker combinations and up to $45 \%$ and $9-11 \%$ of these are $\geq$ grade III $[22,23,36,47-49]$.

\section{Pathogenesis of ICI related GI toxicity}

Immune-related diarrhea associated with ICI treatments is the result of underlying colonic inflammation. In two retrospective studies, it has been shown that patients with a predominance of bacteria from the Bacteroidetes phylum had reduced rates of ipilimumab-induced colitis but underlying mechanism is not known. We need additional research to understand the mechanism of this microbiatal pattern and also to determine the role of manipulation of the microbiota with dietary intervention or use of probiotics or antibiotics in reducing the risk of colitis or other immune related adverse events in cases treated by ICI. On the other hand immunosuppression for the treatment of irAEs may increase the risk of opportunistic infections such as Aspergillus fumigatus pneumonia, cytomegalovirus hepatitis, and pneumocystis pneumonia [49].

\section{Clinical presentation and diagnosis}

Gastrointestinal toxicity of anti-CTLA-4 antibodies: Most common symptom of anti-CTLA-4-induced enterocolitis is diarrhea and is seen in up to $92 \%$ of patients. Other symptoms are vomiting, abdominal pain, hematochezia, weight loss and fever. About one-third of the patients have concomittant enteritis and colitis but diarrhea may be related due to enteritis alone in some cases [50]. There is urgency but there is no blood in stool samples. Nausea, vomiting, early satiety, bloating may be seen in cases with upper GI involvement. Oral ulcers and anal lesions such as fistulas, abscesses, fissures have been reported. Extra-intestinal manifestations of enterocolitis are arthralgia, endocrine disorders, skin dsiorders, hepatitis, nephritis and pancreatitis. Diarrhea appears usually in 6-8 weeks after initiation of treatment [22,51]. Half life of ipilimumab is 2 weeks but biological effect may persist for longer time after drug clearance. For this reason time of onset of GI toxicity is not clear. GI symptoms may occur during 1-10 infusions of antiCTLA-4. Enterocolitis may occur several months after the last dose of ipilimumab and must be considered in cases not actively receiving this antibody [41].

Laboratory findings: Abnormal laboratory findings are anemia, high CRP and hypoalbuminemia. Fecal calprotectin has been found to be increased. Stool cultures for bacterial, parasitic and viral pathogens including Salmonella, Shigella, Campylobacter, Yersinia, Vibrio, Aeromonas, Clostridium difficile, rotavirus, norovirus, Escherichia coli O157:H7/shiga toxin, Cryptosporidium, Giardia must be done. Antineutrophil cytoplasmic antibodies have been found in the minority of the cases. Underlying infection must be ruled out in all cases with GI problems [7,52-56].

Imaging: Abdominal imaging is not necessary in grade I diarrhea but abdominal CT is useful in cases with abdominal pain and $\geq$ grade II diarrhea. CT findings are non specific but are useful to rule out some complications including bowel perforation, abscess, toxic megacolon [57]. Mesenteric vessel engorgement, marked thickening of bowel wall, mucosal hyperenhancement and fluid-filled colon are the most commonly detected findings in abdominal CT in cases with ICI related colitis. There are 3 patterns of colonic inflammation:

a-Diffuse colitis pattern of colonic wall thickening,

b-Segmental colitis associated with diverticulosis,

c-Isolated rectosigmoid colitis without diverticulosis [58].

Endoscopy must be done in cases with bloody diarrhea and persistent and/or $\geq$ grade II diarrhea to confirm the ICI related GI involvement and also to exclude other etiolgic factors. Flexible sigmoidoscopy and biopsies of the left colon can be diagnostic in approximately $95 \%$ of cases with ipilimumab-induced colitis. Ipilimumab-induced colitis generally shows continuous pattern for colonic inflammation with mucosal edema, erythema and diffuse and shallow ulcers but these are no specific for ICI related colitis [59]. On the other hand it is unclear whether sigmoidoscopy is sufficient in cases with PD-1/ PDL1 inhibitor toxicity [50]. Small intestinal and colonic inflammation with PD-1/PD-L1 blockers are seen less prominent by endoscopy. Histopathologic features associated with PD-1/PD-L1 blockers are:

a-Active colitis with neutrophilic inflammation,

b-Increased intra-epithelial lymphocytes, and increased numbers of apoptotic crypt epithelial cells.

c-Rare granuloma formation,

d- Chronicity findings are limited or absent,

e-Lymphocytic colitis may be seen in some patients $[59,60]$.

Prediction of ipilimumab-related colitis: There is no specific biomarker but baseline microbiota composition may predictive for this entity. Increase in bacterium phylum species at baseline has been found to be related with the low risk of colitis while Faecalibacterium prausnitzii and Gemmier formicilis have been found to be related with higher risk of colitis [61,62].

Gastrointestinal toxicity associated with anti-PD-1 antibodies: There is limited data about this matter, irAEs are seen less frequently in cases treated by PD- 1 blockers as compared with ipilimumab. Grade $\geq$ III toxicity is seen in $1-2 \%$ of the cases $[23,63]$. The most commonly 
reported side effects are diarrhea, nausea, vomiting and abdominal pain and median time to onset of GI toxicity is 3 months. Endoscopic findings are variable from normal mucosa to signs of inflammation including mild erythema, mucosal friability or ulceration. Histologic findings are expansion at lamina propria, villus blunting, intra-epithelial neutrophils and increased crypt/gland apoptosis but intra-epithelial lymphocytes are seen less likely [64].

It has been reported 4 patterns associated with anti-PD- 1 associated GI toxicity:

1-Acute colitis similar to colitis induced by anti-CTLA-4 antibody,

2-Microscopic colitis,

3-Upper GI involvement,

4-Pseudo-obstruction

GI toxicity associated with PD-1 blockers are sensitive to corticosteroid with $87.5 \%$ response rate [65].

Gastrointestianl toxicity of combined anti-CTLA-4 and antiPD-1 antibodies: Data about combined using is relatively limited. Diarrhea and colitis appear earlier, more frequently and with higher grade toxicities $[23,66,67]$. Pancreatitis and small bowel enteritis have been reported and requires discontinuation of treatment. Severity of ICI-related GI tract toxicity and diagnostic tools have been shown in Table 3.

\section{Diffrential diagnosis in cases with ICI treated cases with GI symptoms}

Tumor related signs and symtoms and GI infections are the main diagnostic problems in cases with ipilimumab-induced enteropathy. Stool analyses for bacterial eneteropathogens and Clostridium difficile toxin must be evaluated in all cases receiving ipilimumab and severe diarrhea. CMV reactivation may be seen in these cases and must be considered in all cases [68].

Endoscopic lesions are erythema, loss of vascular pattern, erosions and ulcerations. Most of the involved sites of the GI tract are sigmoid colon and rectum; flexible sigmoidoscopy is sufficient in some cases, however colonic lesions are more extensive and may extend proximal in two thirds of the cases. Patchy discontinuous endoscopic lesions are detected in half of the cases. Diagnosis must be confirmed by biopsies done by sigmoidoscopy and/or colonoscopy. Hitopathological findings are characterized by diffuse or patchy infiltration with neutrophils, eosinophils suggesting acute colitis. These findings are different from the lesions detected in chronic inflammatory bowel diseases but in some cases granulomas, basal plasmacytosis and crypt abnormalities (atrophy, distortion, branching, budding) mimicking inflammatory bowel disease may be seen. Upper GI signs and symptoms such as dysphagia, epigastric pain and endoscopically detected oesophagial ulcerations, gastritis and duodenitis have been reported. Chronic, mild, patchy inflammation in the stomach and duodenum have been reported in half of the cases with anti-CTLA4-induced enterocolitis. Histopathologically crypt distortion, focal or heterogenous villus shortening, increase in eosinophils and mononuclear inflammation are seen in the lamina propria $[7,17]$.

\section{Management}

Oral hydration is sufficient in cases with mild diarrhea. Dietary recommendations are not clear enough: banana, applesauce, toast diet, boiled vegetables, starches, cereals, crackers and soup may be useful. However it must be avoided from dietary supplements with high osmolality, foods with high fat and dairy due to the possibility of secondary lactase insufficiency in cases with small intestinal mucosal damage [7]. Anti-diarrheal drugs and electrolyte supplementation are sufficient in cases with mild diarrhea and anti-CTLA- 4 treatment can be continued in these cases [41]. Loperamide should be used at low doses and only in patients with grade I diarrhea [17]. Corticosteroids should be used in cases with mild symptoms: grade I diarrhea/colitis persisting more than 2 weeks or $\geq$ grade II diarrhea with without infectious etiology. Budesonide $9 \mathrm{mg}$ daily at least 4 weeks is used in cases with grade I diarrhea/colitis persisting for more than 2 weeks and then tapered by $3 \mathrm{mg}$ increments for a total of $4-6$ weeks. Budesonide has been used to prevent occurrence of anti-CTLA-4-induced enterocolitis in 2 randomised trials but it has not been found to be useful $[17,69]$.

Colonic perforation may be seen and subtotal colectomy and ileostomy or sigmoidostomy must be done in these cases due to severe inflammation of the remaining colon in the postoperative phase [45].

Prednisone $1 \mathrm{mg} / \mathrm{kg}$ daily can be given to patients with persistent grade I diarrhea and not responding to budesonide or patients with grade II diarrhea/colitis for more than 3 days. In patients responding, prednisone is gradually tapered by 5 to $10 \mathrm{mg}$ weekly, and prednisone is discontinued over 4 to 6 weeks. Patients with symptoms associated with severe enterocolitis ( $\geq$ grade III diarrhea/colitis) must be hospitalized and anti-CTLA-4 therapy must be stopped. Intravenous fluids,

Table 3. Diagnostic tools to evaluate the gastrointestinal toxicity associated with immune checkpoint inhibitors

\begin{tabular}{|c|c|c|}
\hline Diagnostic tool & Grade of toxicity & Which test \\
\hline \multirow[t]{2}{*}{ Laboratory studies } & Grade I-IV diarrhea without risk factors & $\begin{array}{l}\text { Bacterial cultures in stool samples } \\
\text { Salmonella, } \\
\text { shigella, } \\
\text { Campylobacter, } \\
\text { Ecoli 0157:H7/shiga toxin } \\
\text { Stool lactoferrin } \\
\text { C difficile }\end{array}$ \\
\hline & $\begin{array}{l}\text { Grade I-IV diarrhea with risk factors (travelers' diarrhea, } \\
\text { seafood or shellfish exposure) }\end{array}$ & $\begin{array}{l}\text { Vibrio } \\
\text { Aeromonas } \\
\text { Listeria } \\
\text { Yersinia } \\
\text { Cryptosporidium stool antigen ova and parasites } \\
\text { Giardia stool antigen }\end{array}$ \\
\hline Endoscopy & Grade II-IV diarrhea & $\begin{array}{l}\text { Flexible sigmoidoscopy or colonoscopy } \\
\text { Upper endoscopy (in patients with upper GI symptoms) }\end{array}$ \\
\hline Imaging & $\begin{array}{l}\text { Grade II-IV diarrhea and abdominal pain } \\
\text { Grade III-IV diarrhea }\end{array}$ & Abbdominal CT scan \\
\hline
\end{tabular}

Note: This table has been modified from NCCN and ESMO guidelines. 
supplementation of electrolytes, and intravenous steroids: $1-2 \mathrm{mg} / \mathrm{kg}$ per day of methylprednisolone are important in the management of these cases. In patients responding to methylprednisolone an equivalent dose of oral prednisone can be used. the duration of steroid in these cases is not clear but it is advised to discontinue within 6 to 8 weeks or 8-12 weeks $[7,41$,$] . Steroid dose may be increased if patient does not respond$ to IV steroids within 3-5 days or showing relapse while receiving steroid; those patients must be defined as steroid refractory and may be treated with tumor necrosis factor-alpha inhibitor infliximab (5-10 $\mathrm{mg} / \mathrm{kg}$ ). Mycophenolate mofetil is an alternative if infliximab cannot be used $[7,38,40,42,45]$.

Vedolizumab is a humanized gut-specific monoclonal antibody targeting integrin $\alpha 4 \beta 7$ may be an alternative to infliximab in cases with steroid-refractory and/or dependent enterocolitis. It has been found to be useful in 6 of 7 cases steroid-dependent or steroidrefractory ipilimumab-induced enterocolitis. This finding suggests the vedolizumab as potential choice to infliximab but additional evidence is necessary for the efficacy of this drug $[2,17,70,71]$.

Elevated levels of interleukin-17 has been reported in patients with ipilimumab-induced colitis and interleukin-17 elevations have been observed in preclinical models of colitis [71-73]. These findings suggest the using interleukin-17 blockade as a strategy for treating colitis induced by ICI. However, there is also a theoretical risk of decrease of antitumor effects of ICI [58].

Follow up and long term implications: It has been shown many times that ipilimumab-induced entero-colitis is associated with better response to underlying malignancy and survival. The use of corticosteroids or infliximab are not associated with response to ipilimumab $[40,42,74]$. Histologic or endoscopic inflammation may be seen after several months of enterocolitis and it is not clear whether these changes evolve into chronic inflammatory bowel disease. Repeated administartion of ipilimumab in cases developing enterocolitis may cause relapse [45]. In clincal practice nivolumab and ipilimumab may be used sequentially and the development of enterocolitis with first antibody is not predictive for the development of GI toxicity with

Table 4. Management of colitis and diarrhea associated with ICI

\begin{tabular}{|c|c|c|}
\hline Symptom grade & Symptom evaluation & Management \\
\hline Mild: grade I & $<3$ liquid stools/daily, feeding well, & $\begin{array}{l}\text { ICI can be continued, symptomatic management, } \\
\text { Oral fluids, loperamide, to avoid from high fibre } / \mathrm{lactose} \text { diet } \\
\text { If grade I persists }>14 \text { days prednisolone: } 0.5-1 \mathrm{mg} / \mathrm{kg} / \text { day (non-enteric coated) or } \\
\text { budesonide } 9 \mathrm{mg} \text { bd }\end{array}$ \\
\hline Moderate: grade II & 4-6 liquid stools daily, nausea or nocturnal episodes & $\begin{array}{l}\text { If possible, outpatient management } \\
\text { If not possible ICI must be withheld } \\
\text { IV methylprednisolone: } 1 \mathrm{mg} / \mathrm{kg} / \mathrm{day} \\
\text { No response in } 2-3 \text { days: increase dose } 2 \mathrm{mg} / \mathrm{kg} / \mathrm{day} \\
\text { Consider infliximab } \\
\text { If infliximab-refractory, consider vedolizumab }\end{array}$ \\
\hline $\begin{array}{l}\text { Severe } \\
\text { Grade III-IV }\end{array}$ & $>4-6$ liquid stools daily or if episodes within $1 \mathrm{~h}$ of eating & $\begin{array}{l}\text { ICI must be permanently withheld } \\
\text { Require hospitalization and isolation until infection excluded } \\
\text { IV methylprednisolone: } 1-2 \mathrm{mg} / \mathrm{kg} / \mathrm{day} \\
\text { No improvement in } 72 \mathrm{~h} \text { or worsening } \\
\text { Review diet: nothing by mouth, clear fluids, TPN } \\
\text { Early surgical review if bleeding, pain or distention } \\
\text { Infliximab } 5 \mathrm{mg} / \mathrm{kg} \\
\text { If no perforation/sepsis/TB, hepatitis/NYHA III/IV CHF } \\
\text { Can repeat } 2 \text { weeks later } \\
\text { Other immunosuppressive options: MMF } 500-1000 \mathrm{mg} \text { bd or tacrolimu } \\
\text { Consider infliximab } \\
\text { If infliximab-refractory, consider vedolizumab }\end{array}$ \\
\hline
\end{tabular}

Bd: twice daily; CHF: congestive heart failure; CRP: C reactive protein; CT: computed tomography; CBC: complete blood count; ICI: immune checkpoint inhibitor; IV: intravenous; LFT:

liver function test; MMF: mycophenolate mofetil; NYHA: New York Heart Association; PCR: polymerase chain reaction; PJP: Pneumocysti jiroveci pneumonia; TB: Tuberculosis; TFT: thyroid function test; TPN: total parenteral nutrition; vit D: vitamin D Note: This table has been modified from NCCN and ESMO guidelines second antibody [75,76]. For example treatment with nivolumab in a case developing ipilimumab associated colitis is safe. Treatment related irAEs have not been found to be increased in a retrospective analysis covering 576 cases which 312 of them treated with ipilimumab [77]. Table 4 shows the management of colitis and diarrhea associated with ICIs.

\section{Pancreatic complications associated with ICI treatments}

\section{Incidence and clinical outcome}

Elevations in pancreatic enzyme levels, even grade $\geq$ III toxicity are seen in $10-15 \%$ of the cases treated by ICIs, and this situation is frequent in clinical practice. However acute pancreatitis is infrequently seen. Pancreatic enzyme elevations in these cases have been attributed to T-cell-mediated inflammation of other organs producing these enzymes rather than pancreatic inflammation. Elevations in levels of amylase, lipase and amylase+lipase $\geq$ grade III have been reported in $8 \%, 27 \%$ and $10 \%$ of the cases respectively, in a retrospective analysis covering 119 patients treated by nivolumab and/or ipilimumab. In this analysis acute pancreatitis has been reported only in 2 cases [78]. However non-immune-mediated causes of pancreatic enzymes such as pancreatic ductal obstruction associated with metastasis and renal failure causing to delay for the clearance of these enzymes must be considered in the management of these cases [77].

\section{Management}

The clinical significance of pancreatic enzyme elevations without the signs of acute pancreatitis is not clear in cases treated by ICIs. Subclinical pancreatic inflammation may be associated with asymptomatic pancreatic exocrine insufficiency and diabetes but does not require immuno-suppressive treatment, these cases may be monitored by abdominal CT or MRI. For this reason routine assessment of pancreatic enzymes in asymptomatic patients are not necessary [78-81].

First step is the diagnosis of acute pancreatitis and must be suspected in cases with acute onset and persistent epigastric pain. Diagnosis of acute pancreatitis must be confirmed by acute onset
ICI can be continued, symptomatic management, budesonide $9 \mathrm{mg}$ bd

If possible, outpatient management

If not possible ICI must be withhel

Require hospitalization and isolation until infection excluded

Early surgical review if bleeding, pain or distentio

imab $5 \mathrm{mg} / \mathrm{kg}$

Can repeat 2 weeks later

Other immunosuppressive options: MMF 500-1000mg bd or tacrolim 
Table 5. Pancreatic adverse events; symptom evaluations, assessments and management

\begin{tabular}{|l|l|l|l|}
\hline Grading & Symptom evaluation & Assessment & Management \\
\hline Mild & $\leq 3 \mathrm{x}$ ULN amylase and/or $\leq 3 \mathrm{x}$ ULN lipase & $\begin{array}{l}\text { Consider abdominal CT with contrast } \\
\text { Consider magnetic resonance } \\
\text { cholangiopancreatography }\end{array}$ & $\begin{array}{l}\text { Without evidence of pancreatitis: continue ICI } \\
\text { With evidence of pancreatitis: manage as pancreatitis }\end{array}$ \\
\hline Moderate & $\geq 3-5 \mathrm{x}$ ULN amylase and/or $>3 \mathrm{x}$ ULN lipase & $\begin{array}{l}\text { Consider abdominal CT with contrast } \\
\text { Consider magnetic resonance } \\
\text { cholangiopancreatography } \\
\text { Consider other causes of of elevated lipase/ } \\
\text { amylase }\end{array}$ & $\begin{array}{l}\text { Without evidence of pancreatitis: continue ICI } \\
\text { With evidence of pancreatitis: manage as pancreatitis: } \\
\text { hold ICI } \\
\text { Methylprednisolone } 0.5-1 \mathrm{mg} / \mathrm{kg} / \mathrm{d}\end{array}$ \\
\hline Severe & $\geq 5 \mathrm{x}$ ULN amylase and/or $>5 \mathrm{x}$ ULN lipase & $\begin{array}{l}\text { Consider abdominal CT with contrast } \\
\text { Consider magnetic resonance } \\
\text { cholangiopancreatography } \\
\text { Consider other causes of of elevated lipase/ } \\
\text { amylase }\end{array}$ & $\begin{array}{l}\text { Without evidence of pancreatitis: continue ICI } \\
\text { With evidence of pancreatitis: permanently discontinue } \\
\text { ICI } \\
\text { Methylprednisolone 1-2 mg/kg/d }\end{array}$ \\
\hline
\end{tabular}

Note: This table has been modified from NCCN and ESMO guidelines.

and persistent-severe epigastric pain, epigastric pain radiating to the back, elevations of serum lipase/amylase to $\geq 3$ fold the upper limit of normal and also characteristic imaging findings of acute pancreatitis. Immunosuppression with corticosteroids should be used in cases with pancreatitis. Table 5 shows the pancreatic adverse events associated with ICIs, symptom evaluations, assessments and management.

In conclusion GI side effects are common in cases treated by ICIs and patients must be monitored with liver function tests and diarrhea and colitis must be monitored. Low grade toxicities may be treated by symptomatic measures but higher-grade toxicities requires interruption/cessation of the ICI and immunosuppressive drugs according to the severity of toxicity.

\section{Conflict-of-interest}

There is no conflict of interest.

\section{References}

1. Management of Immunotherapy-Related Toxicities (2018) NCCN Clinical Practice Guidelines in Oncology (NCCN Guidelines in partnership with the American Society of Clinical Oncology (ASCO) (Immune Checkpoint Inhibitor-Related Toxicities.

2. Postow MA, Sidlow R, Hellmann MD (2018) Immune-Related Adverse Events Associated with Immune Checkpoint Blockade. $N$ Engl J Med 378: 158-168.

3. Suzman DL, Pelosof L, Rosenberg A, Avigan MI (2018) Hepatotoxicity of immune checkpoint inhibitors: An evolving picture of risk associated with a vital class of immunotherapy agents. Liver Int 38: 976-987.

4. Krummel MF, Allison JP (1996) CTLA-4 engagement inhibits IL-2 accumulation and cell cycle progression upon activation of resting T cells. $J$ Exp Med 183: 2533-2540. [Crossref]

5. Dong H, Strome SE, Salomao DR, Tamura H, Hirano F, et al. (2002) Tumor-associated B7-H1 promotes T-cell apoptosis: a potential mechanism of immune evasion. Nat Med 8: 793-800.

6. Boussiotis VA (2016) Molecular and Biochemical Aspects of the PD-1 Checkpoint Pathway. N Engl J Med 375: 1767-1778. [Crossref]

7. Grover S, Rahma OE, Hashemi N, Lim RM (2018) Gastrointestinal and Hepatic Toxicities of Checkpoint Inhibitors: Algorithms for Management. ASCO Educational Book pp.13-19.

8. Waterhouse P, Penninger JM, Timms E, Wakeham A, Shahinian A, et al. (1995) Lymphoproliferative disorders with early lethality in mice deficient in Ctla-4. Science 270: 985-988.

9. [No authors listed] (2017) The double edge of cancer immunotherapy. Nat Med 23: 137. [Crossref]

10. Turajlic S, Gore M, Larkin J (2018) First report of overall survival for ipilimumab plus nivolumab from the phase III Checkmate 067 study in advanced melanoma. Ann Oncol 29: 542-543. [Crossref]

11. Topalian SL, Sznol M, McDermott DF, Kluger HM, Carvajal RD, et al. (2014) Survival, durable tumor remission, and long-term safety in patients with advanced melanoma receiving nivolumab. J Clin Oncol 32: 1020-1030.
12. Vétizou M, Pitt JM, Daillère R, Lepage P, Waldschmitt N, et al. (2015) Anticancer immunotherapy by CTLA-4 blockade relies on the gut microbiota. Science 350: 10791084.

13. Chaput N, Lepage P, Coutzac C, Soularue E, Le Roux K, et al. (2017) Baseline gut microbiota predicts clinical response and colitis in metastatic melanoma patients treated with ipilimumab. Ann Oncol 28: 1368-1379.

14. Weber JS, Kähler KC, Hauschild A (2012) Management of immune-related adverse events and kinetics of response with ipilimumab. J Clin Oncol 30: 2691-2697. [Crossref]

15. Wang PF, Chen Y, Song SY, Wang TJ, Ji WJ, et al. (2017) Immune-Related Adverse Events Associated with Anti-PD-1/PD-L1 Treatment for Malignancies: A MetaAnalysis. Front Pharmacol 8: 730.

16. Liu J, Blake SJ, Smyth MJ, Teng MWL (2014) Improved mouse models to assess tumour immunity and irAEs after combination cancer immunotherapies. Clin Transp Immunology 3: e22.

17. Haanen JBAG, Carbonnel F, Robert C, Kerr KM, Peters S, et al. (2017) On behalf of the ESMO Guidelines Committee. Management of toxicities from immunotherapy: ESMO Clinical Practice Guidelines for diagnosis, treatment and follow-up. Ann Oncol 28 (Supplement 4): iv119-iv142.

18. Maughan BL, Bailey E, Gill DM, Agarwal N (2017) Incidence of immune-related adverse events with program death receptor-1- and program death receptor-1 liganddirected therapies in genitourinary cancers. Front Oncol 7: 56.

19. Wolchok JD, Kluger H, Callahan MK, Postow MA, Rizvi NA, et al. (2013) Nivolumab plus ipilimumab in advanced melanoma. $N$ Engl J Med 369: 122-133. [Crossref]

20. Hodi FS, O’Day SJ, McDermott DF, Weber RW, Sosman JA, et al. (2010) Improved survival with ipilimumab in patients with metastatic melanoma. $N$ Engl J Med 363: 711-723.

21. Wolchok JD, Neyns B, Linette G, Negrier S, Lutzky J, et al. (2010) Ipilimumab monotherapy in patients with pretreated advanced melanoma: a randomised, doubleblind, multicentre, phase 2, dose-ranging study. Lancet Oncol 11: 155-164.

22. Robert C, Schachter J, Long GV, Arance A, Grob JJ, et al. (2015) KEYNOTE-006 investigators. Pembrolizumab versus ipilimumab in advanced melanoma. $N$ Engl $J$ Med 372: $2521-2532$

23. Larkin J, Chiarion-Sileni V, Gonzalez R, Grob JJ, Cowey CL, et al. (2015) Combined nivolumab and ipilimumab or monotherapy in untreated melanoma. $N$ Engl J Med 373 : 23-34.

24. Boutros C, Tarhini A, Routier E, Lambotte O, Ladurie FL, et al. (2016) Safety profiles of anti-CTLA-4 and anti-PD-1 antibodies alone and in combination. Nat Rev Clin Oncol 13: 473-486.

25. Robert C, Thomas L, Bondarenko I, O'Day S, Weber J, et al. (2011) Ipilimumab plus Dacarbazine for Previously Untreated Metastatic Melanoma. N Engl J Med 364: $2517-$ 2526 .

26. [Crossref] Ribas A, Hodi FS, Callahan M, Konto C, Wolchok J (2013) Hepatotoxicity with combination of vemurafenib and ipilimumab. $N$ Engl J Med 368: 1365-1366.

27. Champiat S, Lambotte O, Barreau E, Belkhir R, Berdelou A, et al. (2016) Managemen of immune checkpoint blockade dysimmune toxicities: a collaborative position paper. Ann Oncol 27: 559-574. 
28. El-Khoueiry AB, Sangro B, Yau T, Crocenzi TS, Kudo M, et al. (2017) Nivolumab in patients with advanced hepatocellular carcinoma (CheckMate 040): an open-label, non-comparative, phase $1 / 2$ dose escalation and expansion trial. Lancet 389: 2492-2502.

29. Kim KW, Ramaiya NH, Krajewski KM, Jagannathan JP, Tirumani SH, et al. (2013) Ipilimumab associated hepatitis: imaging and clinicopathologic findings. Invest New Drugs 31: 1071-1077.

30. Alessandrino F, Tirumani SH, Krajewski KM, Shinagare AB, Jagannathan JP, et al. (2017) Imaging of hepatic toxicity of systemic therapy in a tertiary cancer centre: chemotherapy, haematopoietic stem cell transplantation, molecular targeted therapies, and immune checkpoint inhibitors. Clin Radiol 72: 521-533.

31. Igentler TK, Hassel JC, Berking C, Aberle J, Bachmann O, et al. (2016) Diagnosis, monitoring and management of immune-related adverse drug reactions of anti-PD-1 antibody therapy. Cancer Treat Rev 45: 7-18.

32. Johncilla M, Misdraji J, Pratt DS, Agoston AT, Lauwers GY, et al. (2015) Ipilimumabassociated hepatitis: clinicopathologic characterization in a series of 11 cases. $\mathrm{Am} \mathrm{J}$ Surg Pathol 39: 1075-1084.

33. Kleiner DE, Berman D (2012) Pathologic Changes in Ipilimumab-related Hepatitis in Patients with Metastatic Melanoma. Dig Dis Sci 57: 2233-2240.

34. Suzuki A, Brunt EM, Kleiner DE, Miquel R, Smyrk TC, et al. (2011) The use of liver biopsy evaluation in discrimination of idiopathic autoimmune hepatitis versus druginduced liver injury. Hepatology 54: 931-939.

35. https://www.fda.gov/Drugs/default.htm

36. Naidoo J, Page DB, Li BT, Connell LC, Schindler K, et al. (2015) Toxicities of the anti-PD-1 and anti- PD-L1 immune checkpoint antibodies. Ann Oncol 26: 2375-2391.

37. Ziemer M, Koukoulioti E, Beyer S, Simon JC, Berg T (2017) Managing immune checkpointinhibitor- induced severe autoimmune-like hepatitis by liver-directed topical steroids. J Hepatol 66: 657-659.

38. Chmiel KD, Suan D, Liddle C, Nankivell B, Ibrahim R, et al. (2011) Resolution of severe ipilimumab induced hepatitis after antithymocyte globulin therapy. J Clin Oncol 29: e237-e240.

39. Mellati M, Eaton KD, Brooks-Worrell BM, Hagopian WA, Martins R, et al. (2015) Anti-PD-1 and anti-PDL-1 monoclonal antibodies causing type 1 diabetes. Diabetes Care 38: e137-e138.

40. Horvat TZ, Adel NG, Dang TO, Momtaz P, Postow MA, et al. (2015) Immune-related adverse events, need for systemic immunosuppression, and effects on survival and time to treatment failure in patients with melanoma treated with ipilimumab at Memorial Sloan Kettering Cancer Center. J Clin Oncol 33: 3193-3198.

41. Gupta A, De Felice KM, Loftus EV, Khanna S (2015) Systematic review: colitis associated with anti-CTLA-4 therapy. Aliment Pharmacol Ther 42: 406-417.

42. Beck KE, Blansfield JA, Tran KQ, Feldman AL, Hughes MS, et al. (2006) Enterocolitis in patients with cancer after antibody blockade of cytotoxic T-lymphocyte-associated antigen 4. J Clin Oncol 24: 2283-2289.

43. Yervoy (2017) Highlights of prescribing information pp. 1-20.

44. Eggermont AM, Chiarion Sileni V, Grob JJ Dummer R, Wolchok JD, et al. (2016) Prolonged survival in stage III melanoma with ipilimumab adjuvant therapy. $N$ Engl J Med 375: 1845-1855.

45. Marthey L, Mateus C, Mussini C, Nancey S, Grange F, et al. (2016) Cancer immunotherapy with anti-CTLA-4 monoclonal antibodies induces an inflammatory bowel disease. J Crohns Colitis 10: 395-401.

46. Johnson DB, Sullivan RJ, Ott PA, Carlino MS, Khushalani NI, et al. (2016) Ipilimumab therapy in patients with advanced melanoma and preexisting autoimmune disorders. JAMA Oncol 2: 234-240.

47. Robert C, Long GV, Brady B, Dutriaux C, Maio M, et al. (2015) Nivolumab in previously untreated melanoma without BRAF mutation. $N$ Engl J Med 372: 320-330.

48. Weber JS, D'Angelo SP, Minor D, Hodi FS, Gutzmer R, et al. (2015) Nivolumab versus chemotherapy in pa?? ents with advanced melanoma who progressed after antiCTLA-4 treatment (CheckMate 037): a randomised, controlled, openlabel, phase 3 trial. Lancet Oncol 16: 375-384.

49. Vétizou M, Pitt JM, Daillère R, Lepage P, Waldschmitt N, et al. (2015) Anticancer immunotherapy by CTLA-4 blockade relies on the gut microbiota. Science 350: 1079-1084.

50. Messmer M, Upreti S, Tarabishy Y, Mazumder N, Chowdhury R, et al. (2016) Ipilimumab-induced enteritis without colitis: a new challenge. Case Rep Oncol 9: 705713.
51. Weber JS, Kähler KC, Hauschild A (2012) Management of immune-related adverse events and kinetics of response with ipilimumab. J Clin Oncol 30: 2691-2697. [Crossref]

52. Shane AL, Mody RK, Crump JA, Tarr PI, Steiner TS, et al. (2017) Infectious Diseases Society of America clinical practice guidelines for the diagnosis and management of infectious diarrhea. Clin Infect Dis 65: e45-e80.

53. Riddle MS, DuPont HL, Connor BA (2016) ACG clinical guideline: diagnosis, treatment, and prevention of acute diarrheal infections in adults. Am J Gastroenterol 111: 602-622.

54. Lord JD, Hackman RC, Moklebust A, Thompson JA, Higano CS, et al. Refractory colitis following anti-CTLA4 antibody therapy: analysis of mucosal FOXP3 T cells. Dig Dis Sci 55: 1396-1405.

55. Hodi FS, O'Day SJ, McDermott DF, Weber RW, Sosman JA, et al. (2010) Improved survival with ipilimumab in patients with metastatic melanoma. $N$ Engl J Med 363 . 711-723. [Crossref]

56. Berman D, Parker SM, Siegel J, Weber RW, Sosman JA, et al. (2010) Blockade of cytotoxic T-lymphocyte antigen-4 by ipilimumab results in dysregulation of gastrointestinal immunity in patients with advanced melanoma. Cancer Immun 10: 11

57. Nishino M, Ramaiya NH, Hatabu H, Hodi FS (2017) Monitoring immunecheckpoint blockade: response evaluation and biomarker development. Nat Rev Clin Oncol 14: 655-668

58. Kim KW, Ramaiya NH, Krajewski KM, Shinagare AB, Howard SA, et al. (2013) Ipilimumab-associated colitis: CT findings. AJR Am J Roentgenol 200: W468-474 [Crossref]

59. Marthey L, Mateus C, Mussini C, Nachury M, Nancey S, et al. (2016) Cancer immunotherapy with anti-CTLA-4 monoclonal antibodies induces antiinflammatory bowel disease. J Crohn's Colitis 10: 395-401.

60. Chen JH, Pezhouh MK, Lauwers GY, Masia R (2017) Histopathologic Features of Colitis Due to Immunotherapy With Anti-PD-1 Antibodies. Am J Surg Pathol 41: 643654. [Crossref]

61. Dubin K, Callahan MK, Ren B (2016) Intestinal microbiome analyses identify melanoma patients at risk for checkpoint-blockade-induced colitis. Nat Commun 7 : 10391.

62. Chaput N, Lepage P, Coutzac C, Soularue E, Le Roux K, et al. (2017) Baseline gut microbiota predicts clinical response and colitis in metastatic melanoma patients treated with ipilimumab. Ann Oncol 28: 1368-1379.

63. Robert C, Ribas A, Wolchok JD, Hodi FS, Hamid O, et al. (2014) Anti-programmeddeath-receptor-1 treatment with pembrolizumab in ipilimumab-refractory advanced melanoma: a randomised dose-comparison cohort of a phase 1 trial. Lancet 384: 1109-1117.

64. Gonzalez RS, Salaria SN, Bohannon CD, Huber AR, Feely MM, et al. (2017) PD-1 inhibitor gastroenterocolitis: case series and appraisal of 'immunomodulatory gastroenterocolitis'. Histopathology 70: 558-567.

65. Collins M, Michot JM, Danlos FX (2017) Gastrointestinal immune related adverse events associated with programmed-Death 1 blockade. J Crohns Colitis 11(suppl 1): S237.

66. Hodi FS, Chesney J, Pavlick AC, Robert C, Grossmann KF, et al. (2016) Combined nivolumab and ipilimumab versus ipilimumab alone in patients with advanced melanoma: 2- year overall survival outcomes in a multicentre, randomised, controlled, phase 2 trial. Lancet Oncol 17: 1558-1568.

67. Postow MA, Chesney J, Pavlick AC, Robert C, Grossmann K, et al. (2015) Nivolumab and ipilimumab versus ipilimumab in untreated melanoma. N Engl J Med 372: 2006-2017.

68. Lankes K, Hundorfean G, Harrer T, Pommer AJ, Agaimy A, et al. (2016) Anti-TNFrefractory colitis after checkpoint inhibitor therapy: Possible role of CMV-mediated immunopathogenesis. Oncoimmunology 5: e1128611.

69. Weber J, Thompson JA, Hamid O, Minor D, Amin A, et al. (2009) A randomized, double-blind, placebo-controlled, phase II study comparing the tolerability and efficacy of ipilimumab administered with or without prophylactic budesonide in patients with unresectable stage III or IV melanoma. Clin Cancer Res 15: 5591-5598.

70. Yanai, Nakamura S, Matsumoto T (2017) Nivolumab-Induced Colitis Treated by Infliximab. Clin Gastroenterol Hepatol 15: e80-80e81. [Crossref]

71. Bergqvist V, Hertervig E, Gedeon P, Kopljar M, Griph H, et al. (2017) Vedolizumab treatment for immune checkpoint inhibitor-induced enterocolitis. Cancer Immunol Immunother 66: 581-592.

72. Callahan M (2011) Evaluation of serum IL-17 levels during ipilimumab therapy: correlation with colitis. J Clin Oncol 29: Suppl:2505. 
73. Harbour SN, Maynard CL, Zindl CL, Schoeb TR, Weaver CT (2015) Th17 cells give rise to Th1 cells that are required for the pathogenesis of colitis. Proc Natl Acad Sci U $S$ A 112: 7061-7066. [Crossref]

74. Arriola E, Wheater M, Karydis I, Thomas G, Ottensmeier C (2015) Infliximab for IPILIMUMAB-Related Colitis-Letter. Clin Cancer Res 21: 5642-5643. [Crossref]

75. Weber JS, D'Angelo SP, Minor D Hodi FS, Gutzmer R, Neyns B, et al. (2015) Nivolumab versus chemotherapy in patients with advanced melanoma who progressed after anti-CTLA-4 treatment (CheckMate 037): a randomised, controlled, open-label, phase 3 trial. Lancet Oncol 16: 375-384.

76. Weber JS, Kudchadkar RR, Yu B, Gallenstein D, Horak CE, et al. (2016) Safety, efficacy, and biomarkers of nivolumab with vaccine in ipilimumab-refractory or -naive melanoma.

77. Weber JS, Hodi FS, Wolchok JD, Topalian SL, Schadendorf D, et al. (2017) Safety profi le of nivolumab monotherapy: a pooled analysis of patients with advanced melanoma. J Clin Oncol 35: 785-792.
78. Friedman CF, Clark V, Raikhel AV, Barz T, Shoushtari AN, et al. (2016) Thinking critically about classifying adverse events: incidence of pancreatitis in patients treated with nivolumab + ipilimumab. J Natl Cancer Inst pp. 109.

79. Di Giacomo AM, Danielli R, Guidoboni M, Calabrò L, Carlucci D, et al. (2009) Therapeutic efficacy of ipilimumab, an anti-CTLA-4 monoclonal antibody, in patients with metastatic melanoma unresponsive to prior systemic treatments: clinical and immunological evidence from three patient cases. Cancer Immunol Immunother 58: 1297-1306. [Crossref]

80. Di Giacomo AM, Danielli R, Guidoboni M, Calabrò L, Carlucci D, et al. (2009) Therapeutic efficacy of ipilimumab, an anti-CTLA-4 monoclonal antibody, in patients with metastatic melanoma unresponsive to prior systemic treatments: clinical and immunological evidence from three patient cases. Cancer Immunol Immunother 58: 1297-1306. [Crossref]

81. Postow MA (2015) Managing immune checkpoint-blocking antibody side effects. $A m$ Soc Clin Oncol Educ Book. [Crossref]

Copyright: @2019 Paydas S. This is an open-access article distributed under the terms of the Creative Commons Attribution License, which permits unrestricted use, distribution, and reproduction in any medium, provided the original author and source are credited. 